\title{
ORAÇÕES RELATIVAS: UMA REFLEXÃO SOBRE O USO DESSAS FERRAMENTAS NO ENSINO MÉDIO
}

\author{
RELATIVE CLAUSES: AN OBSERVATION ABOUT THE USAGE OF \\ THIS TOOLS IN THE HIGH SCHOOL
}

\author{
${ }^{1}$ Patrick Silva de Mattos; ${ }^{2}$ Otávio Tadeu Alves Pereira; ${ }^{3}$ Paula Fernanda Eick Cardoso
}

\author{
1 patrickdemattos87@ hotmail.com, Universidade Federal de Pelotas; \\ ${ }^{2}$ pereiraotavioalves@gmail.com, Universidade Federal de Pelotas; ${ }^{3}$ paulaeick@ terra.com.br, \\ Universidade Federal de Pelotas.
}

\begin{abstract}
Resumo
O presente trabalho versará sobre as estratégias de formação das orações relativas empregadas no português brasileiro, vinculando-se, portanto, à área de Linguística. O objetivo deste estudo consiste em identificar o processo preferencialmente usado pelos candidatos ao vestibular da Universidade Federal de Pelotas (UFPel), com o intuito de fazer um diagnóstico do conhecimento linguístico dos alunos de ensino médio em um contexto de uso monitorado de linguagem. Esse diagnóstico terá repercussões significativas no trabalho com a língua materna, visto que poderá trazer subsídios para o emprego de metodologias de trabalho capazes de aprimorar o conhecimento de linguagem dos estudantes brasileiros. Para alcançar esse objetivo, foram analisadas, até o presente momento, cinquenta redações. Parte dos candidatos cujos textos foram analisados parecem evitar as construções relativas, produzindo redações com estruturas sintáticas indicadoras de um nível de complexidade e de planejamento relativamente rasos. Por outro lado, identificou-se, em certas dissertações, o uso apropriado do relativo com a preposição exigida pelo verbo, o que parece indicar a sobrevivência dessa estrutura na linguagem escrita dos estudantes brasileiros, e a necessidade de emprego de uma metodologia de trabalho capaz de ampliar o conhecimento de linguagem dos alunos de ensino médio.
\end{abstract}

Palavras chaves: Orações Relativas, Pronomes Relativos, Sintaxe, Linguística.

\begin{abstract}
The present work will talk about the strategies used to construct the relative clauses in the Brazilian portuguese, linking, therefore, the field of Linguistics. The aim of this study is identifying the process preferentially used by the candidates to the university entrance examination of the Universidade Federal de Pelotas (UFPel), with the purpose of doing a diagnosis of the linguistic knowledge of the high level students in a language monitored context. This diagnosis will have significant repercussions in the work with the mother language, since it might bring subsidies for the usage of working methodologies capable of improving the language knowledge of the Brazilian students. To achieve this aim, we analyzed 50 essays and part of the candidates whose the tests were analyzed seem avoid the relative constructions, producing essays with a level of shallow syntactic complexity. On the other hand, in certain essays, the appropriate usage of the relative with the required preposition by the verb indicates the survival of this structure in Brazilian students writing language and the using necessity of a work methodology able to extend the language knowledge of the high level students.
\end{abstract}

Keywords: Relative Clauses, Relative Pronouns, Syntax, Linguistics. 


\section{INTRODUÇÃO}

O reconhecimento de diferentes formas de expressão existentes na língua portuguesa e a capacidade de adequá-las a diversos contextos comunicativos são habilidades essenciais a um falante proficiente de língua. Além disso, o emprego apropriado das orações relativas revela um domínio sofisticado dos recursos disponíveis na língua, assim como proporciona ao falante a possibilidade de interagir com mais eficácia em situações as quais preveem um maior monitoramento na escrita e/ou na fala.

O presente trabalho pretende, portanto, identificar a(s) estratégia(s) empregada(s) pelos candidatos ao vestibular da UFPel para formação das orações relativas em que apareçam verbos transitivos indiretos ou verbos transitivos diretos e indiretos, os quais exigem um complemento regido por preposição - assim como prevê a tradição gramatical -, com o intuito de procurar explicitar o conhecimento linguístico dos estudantes brasileiros de ensino médio. Esse estudo repercutirá certamente no trabalho com a língua materna, pois poderá permitir o emprego de metodologias capazes de ampliar a capacidade de expressão linguística e de compreensão textual desses alunos.

\section{CONSIDERAÇÕES TEÓRICAS ACERCA DOS PRONOMES RELATIVOS}

No português brasileiro (doravante $\mathrm{PB}$ ), há três estratégias diferentes para formação de orações relativas com verbos que exijam um complemento ou uma locução adverbial regidos por preposição. Segundo Bagno (2002), essas estratégias são: (a) Relativa Padrão, (b) Relativa Copiadora, (c) Relativa Cortadora. Vejamos a seguir em que consiste cada uma delas:

a) RELATIVA PADRÃO: caracteriza-se pela presença de uma preposição antecedendo o pronome relativo. Essa preposição cumpre as exigências de transitividade do verbo a que o pronome se liga com o intuito de lhe complementar o sentido.

(1) “O jogador a que me refiro foi punido exemplarmente pela Comissão Disciplinar da FIFA."

Se desmembrássemos o período composto acima em dois períodos simples, teríamos:

(2) (i) O jogador foi punido exemplarmente pela Comissão Disciplinar da FIFA.

(ii) Refiro-me ao jogador. 
Quando comparamos o período composto em (1) com os períodos simples em (2), percebemos que o período composto em (1) representa uma forma mais econômica de expressão, visto que evita a repetição do substantivo "jogador". O pronome relativo "que”, além de retomar uma informação previamente apresentada na frase, é capaz de desempenhar, dentro da oração relativa, a função sintática desempenhada pela segunda ocorrência de “jogador” em (2). Além disso, a preposição requerida pelo verbo pronominal "referir-se” está presente tanto em (1) quanto em (2ii). Em (1), ela antecede o relativo "que" e, em (2ii), ela antecede o sintagma "o jogador".

Essa estratégia de formação das orações relativas é a única aceita pelas gramáticas tradicionais, como, por exemplo, podemos encontrar em Cunha \& Cintra (2008). Portanto, segundo a visão da tradição gramatical, em qualquer contexto comunicativo, monitorado ou não e mais ou menos formal, deveríamos falar e escrever frases do seguinte tipo:

(3) (i) A Comissão Técnica com que os jogadores contam é extremamente capaz.

(ii) Os obstáculos contra os quais os jogadores lutam são muitos.

(iii) $\mathrm{O}$ jogador por cuja volta ao time anseio partiu há três semanas.

Nas frases acima, há sempre uma preposição regendo um pronome relativo (“com”, "contra" e "por"), todas elas exigidas pela transitividade verbal.

b) RELATIVA COPIADORA: caracteriza-se pela presença de um pronome cópia na posição de complemento e/ou de locução adverbial. Nessa estrutura, o pronome relativo serve apenas para unir a oração subordinada à oração principal. Ele é incapaz de desempenhar qualquer função sintática, uma vez que esse papel cabe ao pronome cópia. Segundo Collischonn (2003), as relativas copiadoras são construções rejeitadas pelo atual modelo escolar. Observemos as frases abaixo.

(4) O jogador que eu gosto muito dele atua na seleção colombiana.

Em (4), a função de objeto indireto do verbo "gostar" é desempenhada por "dele" - contração do pronome "ele" com a preposição "de". Embora essa estratégia seja condenada pelas gramáticas tradicionais, ela devolve ao português suas propriedades analíticas, as quais não são identificadas na estratégia padrão, que é extremamente sintética. 
Na estratégia padrão, o pronome relativo desempenha três funções: (a) une a oração subordinada à principal; (b) retoma uma informação previamente mencionada dentro da frase - o antecedente; (c) desempenha uma função sintática dentro da oração subordinada; por isso, a relativa padrão é um corpo estranho às estruturas sintáticas do PB.

Para eliminar essa estranheza, os falantes recorrem ao processo de análise identificado em (4). Nessa frase, como já vimos, há uma divisão das funções, pois a palavra "que" serve apenas para unir orações, funcionando como uma conjunção. A função sintática de complemento verbal é desempenhada pelo item "dele". O mesmo ocorre, por exemplo, em (5).

(5) Neymar é um jogador que ele acabou sofrendo uma lesão muscular.

Na frase acima, também ocorre a separação das diversas partes constituintes de um todo, o que caracteriza a análise. O relativo não acumula funções, pois novamente ele serve apenas para unir a oração subordinada à principal. $\mathrm{O}$ elemento que atua como sujeito é o pronome pessoal do caso reto "ele".

c) RELATIVA CORTADORA: caracteriza-se pelo apagamento da preposição exigida pelo verbo, como pode ser observado na frase abaixo.

(6) Esse é o jogador que o time inteiro confia.

Se desmembrássemos o período composto acima, obteríamos os dois seguintes períodos simples:

(7) (i) Esse é o jogador.

(ii) $\mathrm{O}$ time inteiro confia no jogador.

A presença da preposição "em" é obrigatória entre o complemento "jogador" e o verbo "confiar"; por isso temos a forma "no" - contração da preposição "em" com o artigo "o". Essa preposição, entretanto, não é identificada na oração relativa em (6).

Segundo Bagno (2002), a relativa cortadora é a estratégia preferida pelos brasileiros, e a motivação para essa preferência é de natureza sociolinguística. Para não parecer pedante ao utilizar a estratégia padrão nem pouco instruído ao empregar a relativa copiadora, a qual está 
associada às modalidades de linguagem usadas pela população com baixo nível de escolaridade, os brasileiros optam pela relativa cortadora.

Há também uma motivação de natureza sintática para o emprego da relativa cortadora: o ouvinte ou o leitor é capaz de reconhecer a preposição que foi apagada, pois leva em consideração seu conhecimento de linguagem para compreender frases produzidas em sua língua materna e também para construí-las. Ele sabe que "quem confia, confia em alguém"; por isso há a possibilidade de a preposição ser apagada na construção da relativa.

\section{METODOLOGIA}

O presente trabalho baseia-se na análise de redações produzidas por candidatos ao vestibular de verão/2007 da UFPel. Após a leitura dos textos, procuramos localizar as orações relativas construídas pelos candidatos. Em seguida, selecionamos aquelas em que aparecem ou em que deveriam aparecer pronomes relativos regidos por uma preposição, com o intuito de identificar as estratégias empregadas pelos candidatos e, também, estabelecer o percentual de uso de cada uma delas, utilizando a classificação proposta por Bagno (2002).

Após a identificação dos pronomes relativos, em seus diversos contextos de uso, procurou-se estabelecer uma tabela quantitativa que evidenciasse os resultados encontrados. Esta tabela, assim como outras considerações acerca do que foi encontrado na análise das redações, pode ser vista na próxima sessão: Resultados e Discussões.

Esse tipo de análise toma por base os trabalhos previamente realizados por Bagno (2002), Collischonn (2003), Badaracco (2014) e Cunha \& Cintra (2008).

\section{RESULTADOS E DISCUSSÕES}

Até o presente momento foram analisadas cinquenta redações, as quais revelaram resultados interessantes que começam a ser quantificados. De maneira preliminar, percebemos que, apesar de pelo menos doze anos de ensino formal e normativo nas escolas brasileiras, parte dos candidatos cujos textos foram analisados procura evitar as construções relativas, produzindo redações com nível de complexidade sintática raso. Parece haver uma preferência por estruturas coordenadas, as quais tendem a indicar, inclusive, pouca reflexão sobre o assunto proposto para a dissertação, pois o candidato apenas lista ideias, sem estabelecer as devidas relações entre elas.

Collischonn (2003) corrobora essa afirmação quando diz que o aluno parece poupar-se do uso dessas estratégias de relativização a fim de evitar o emprego equivocado das construções ou mesmo pela ausência de conhecimento dessas estruturas sintáticas. 
A tabela a seguir evidencia o número de casos encontrados, assim como a porcentagem atribuída a eles:

\begin{tabular}{|c|c|c|c|}
\hline & Relativa Padrão & Relativa Cortadora & Relativa Copiadora \\
\hline $\begin{array}{c}\text { Casos encontrados (total de } \\
34)\end{array}$ & $21=61,7 \%$ & $13=38,3 \%$ & $0=0 \%$ \\
\hline
\end{tabular}

Tabela 1 - Resultados quantificados

Pudemos observar um total de trinta e quatro (34) casos de orações relativas, das quais vinte e uma (21) configuram-se como Relativa Padrão, treze (13) como Relativa Cortadora e, já dentro do resultado esperado, nenhuma ocorrência de Relativa Copiadora.

Também dentro do resultado esperado, identificamos em maior número o emprego apropriado do relativo (segundo a GT) com a preposição exigida pelo verbo, o que parece indicar a sobrevivência dessa estrutura na linguagem escrita dos estudantes brasileiros em uso monitorado da linguagem.

Observemos, a título de exemplo, as frases abaixo retiradas dos textos analisados:

(8) "Esses alunos fecham-se em seus mundos, normalmente sem dividir com seus pais, os problemas por que passam na escola..."

(9) "os casos mais preocupantes são os que envolvem atos de violência, nos quais vítimas sofrem ameaças"

(10) “...teve algum apelido do qual não gostava?”

(11) "Se analisarmos os casos graves de violência de alunos nas escolas, em que crianças vão armadas para a escola...”

Apesar de a maioria das orações relativas terem sido construídas por intermédio da Relativa Padrão, o baixo número de ocorrência dessas estruturas gramaticais revela a necessidade de emprego de uma metodologia de trabalho capaz de ampliar o conhecimento de linguagem dos alunos de ensino médio a fim de possibilitar a eles uma maior proficiência na linguagem escrita.

Bagno (2002) e outros linguistas apontam a Relativa Cortadora como sendo a preferida pelos brasileiros atualmente; o uso dessa estrutura gramatical, entretanto, ainda é amplamente condenado pelas gramáticas tradicionais, o que provavelmente leva o candidato, 
estando inserido em um contexto escrito e monitorado da linguagem, a pouco optar pela utilização das estruturas sintáticas com pronome relativo.

\section{CONCLUSÕES}

O presente trabalho demonstra a necessidade de uma análise cuidadosa dos recursos linguísticos empregados pelos estudantes brasileiros com o intuito de explicitar as propriedades da linguagem que utilizam e de buscar metodologias capazes de aprimorar essa linguagem, permitindo uma comunicação mais eficiente.

Embora os textos dos vestibulandos não retratem o uso espontâneo da língua portuguesa, uma vez que foram produzidos em uma situação de controle da linguagem, eles indubitavelmente revelam os conhecimentos internalizados pelos candidatos ao longo de suas diferentes experiências com a língua portuguesa, seja no meio familiar, seja no meio social, seja no meio escolar. A interferência de diversos modelos na construção do saber linguístico dos candidatos oportuniza uma compreensão da vivência escolar sobre a gramática natural do candidato e do trabalho com a língua materna realizado pelo ensino fundamental e médio.

Esses estudos são extremamente relevantes, uma vez que permitem o exame das características da linguagem utilizada por alunos do sistema educacional brasileiro à luz de teorias linguísticas e, além disso, estimulam a reflexão sobre o ensino de língua materna.

Importantes linguistas, como Luft (2002), afirmam que o ensino de língua materna apresenta problemas porque os professores insistem em ensinar teoria gramatical aos alunos, ignorando o fato de que ela é o pressuposto de qualquer ato de fala, por simples que seja.

Bagno (2002) afirma que os professores deveriam fazer o aluno crescer em linguagem, melhorar seu nível vocabular, reconhecer os recursos expressionais da língua, tomar conhecimento das potencialidades do português. Entretanto, a escola tem assumido uma outra prática. Alfabetizado o aluno, persiste a convicção de que ele não sabe a língua, pois ainda não escreve sem erros, na ortografia vigente. Começa então uma obsessão ortográfica, que perseguirá o aluno em todo o percurso escolar.

No que diz respeito às redações, elas são vistas como mera aplicação de regras gramaticais que devem ser memorizadas pelos alunos. As consequências aparecem na avaliação: em vez de privilegiar o conteúdo e a criatividade do aluno, os professores tendem a assinalar implacavelmente todos os erros de grafia, pontuação e sintaxe. O aluno não faz redação para se expandir linguisticamente e manifestar suas emoções ou ideias, nem para aprender a estruturar seus pensamentos por escrito; o aluno faz redação para o professor corrigir. 
Essa atitude acaba por inibir o desenvolvimento linguístico dos alunos e os resultados aparecem com clareza nas pesquisas. A utilização de recursos gramaticais, como os pronomes relativos, evidencia o conhecimento das estruturas linguísticas e serve inclusive para encadear com mais eficácia as ideias que o autor pretende transmitir nos textos. Por outro lado, o desconhecimento desses recursos provoca o emprego excessivo de construções que podem inclusive dificultar a compreensão do texto.

Torna-se, portanto, fundamental um trabalho com a língua materna capaz de potencializar os conhecimentos de linguagem dos alunos, apontando-lhes os diversos recursos disponíveis na língua para a comunicação, a expressão de suas ideias. Um trabalho que possibilite ao aluno crescer em linguagem.

\section{REFERÊNCIAS}

BADARACCO, LUCAS. A Análise da relativização em uma variedade culta do português brasileiro escrito. Pelotas: UFPel, 2014.

BAGNO, MARCOS. Português ou brasileiro? Um convite à pesquisa. São Paulo: Parábola, 2002.

COLLISCHONN, GISELA. O uso de construções relativas em textos dissertativos do CV/2003: algumas reflexões. In Redação Instrumental. Porto Alegre: UFRGS-COPERSE, 2003.

CUNHA, C.; CINTRA, L. F. L. Nova gramática do português contemporâneo.

5. ed. Rio de Janeiro: Lexikon, 2008.

LUFT, C. P. Língua e Liberdade: Por uma nova concepção da língua materna.São Paulo: Ática, 2002. 